\title{
Internalization of Surface Components During Fc-receptor Mediated Phagocytosis by Macrophages
}

\author{
Dorly de Freitas Buchi* and Wanderley de Souza** \\ Laboratório de Ultraestrutura Celular Hertha Meyer, Instituto de Biofísica Carlos Chagas Filho, Universidade \\ Federal do Rio de Janeiro, Ilha do Fundäo, 21949-900, Rio de Janeiro, Brasil
}

Key words: Macrophages/Phagocytosis/Surface components/Lysosome-phagosome fusion

\begin{abstract}
$A B S T R A C T$. Mouse peritoneal resident macrophages efficiently ingest IgG-coated erythrocytes through a phagocytic process mediated by Fc-receptors. During this process surface components of the macrophages, which can be labeled by cationized ferritin and gold-labeled lectins are not interiorized together with the IgGcoated erythrocytes. However, they are internalized through endocytic vesicles and concentrated into vacuoles which are part of the endosomal-lysosomal system. Later on some of these components either are recycled back to the cell surface or are released, due to a process of lysosome-phagosome fusion, into the erythrocyte-containing phagosomes.
\end{abstract}

Interaction of opsonized particles with macrophages via the $\mathrm{Fc}$ receptor $(\mathrm{FcR})$ triggers several cell responses such as activation of NAD(P)H-oxidase, release of lysosomal enzymes, etc. $(24,21,36)$. During Fc-receptormediated phagocytosis macrophages undergo profound shape changes with the active participation of cytoskeletal proteins (13-14). Phagocytosis by macrophages is initiated when particles coated with IgG bind to the Fc receptor exposed on the cell surface. The phagocytic process involves interiorization of part of the macrophage plasma membrane for the formation of the phagocytic vacuole. The mechanism by which FcR ligation signals pseudopod extension and particle engulfing is not known. It has been shown, however, that during the process of ingestion of some particles, components of the plasma membrane, such as transport carriers, are selectively retained in the plasma membrane and they are not observed in the membrane lining the endocytic vacuole (35). However, other components are interiorized and are found in the membrane of the endosomes (Review in 32). The surface properties of the particle and of the phagocytic cell may determine the nature of the components of the phagocytic cell membrane which are interiorized (5). Indeed, it has been shown that opsonization of tachyzoites of Toxoplasma gondii changes the pattern of interiorization of some macrophage membrane components such as anionic sites and NADPH oxidase (7).

* Permanent address: Departamento de Biologia Celular, Setor de Ciências Biológicas, Universidade Federal do Paraná, Curitiba, Brasil.

** To whom correspondence should be addressed.
There are very few studies aiming at the identification of surface components which remain associated with the cell surface or are interiorized during the phagocytic process $(4,6,7,25)$. Sheep red blood cells coated with immunoglobulin $G(E I g G)$ are an excellent marker to analyze the nature of surface componens that are interiorized during a Fc-receptor-mediated phagocytosis. One approach to analyze this process is to label the macrophage surface with ligands such as cationized ferritin and gold-labelled lectins and then allow interaction of IgG-coated erythrocytes to take place, following the fate of the probes. This approach, as well as the freezefracture technique which allows the examination of intramembranous particles, were used in the present study.

\section{MATERIALS AND METHODS}

Macrophages. Resident macrophages were collected from peritoneal cavities of normal Swiss mice. Immediately after killing the animals with ether, their peritoneal cavities were washed with Hank's balanced salt solution and the cells were plated on plastic flasks or on glass coverslips. After incubation for 30 minutes at $37^{\circ} \mathrm{C}$, the non-adherent cells were removed and Eagle's medium with $10 \%$ fetal calf serum (FCS) was added. After incubation at $37^{\circ} \mathrm{C}$ for $24 \mathrm{~h}$ macrophage cultures were rinsed with Eagle's medium without FCS and used for the experiments.

Preparation of EIgG. Sheep red blood cells were washed by centrifugation three times with PBS. Erythrocytes were then incubated with a subagglutinating concentration of the rabbit-anti-sheep red blood cells IgG (Cordies Laboratories) 
for 60 minutes at room temperature, washed and resuspended in Eagle's medium without serum.

Endocytic index. After cultivation for $24 \mathrm{~h}$ at $37^{\circ} \mathrm{C}$, the resident macrophage cultures were washed and allowed to interact for 15,30 and 60 minutes with $\mathrm{EIgG}$ resuspended in Eagle's medium without serum. The erythrocyte suspension was adjusted so that a $10: 1$ erythrocyte-macrophage ratio was obtained. After incubation the cells were rinsed, fixed with Bouin's fixative, stained with Giemsa and mounted with a Permount drop. For each coverslip about 100 macrophages were examined with a Zeiss Universal microscope using an immersion objective. The percentage of macrophages with ingested EIgG and the mean number of intracellular particles per macrophage was determined. The endocytic index was calculated by multiplying the percentage of macrophages with ingested EIgG and the mean number of EIgG per macrophage.

Scanning electron microscopy. The macrophages were plated on coverslips, allowed to interact with EIgG, fixed in $2.5 \%$ glutaraldehyde in $0.1 \mathrm{M}$ cacodylate buffer, $\mathrm{pH} 7.2$, dehydrated in ethanol, critical point dried in $\mathrm{CO}_{2}$, coated with a thin layer of gold and observed in a scanning electron microscope.

Transmission electron microscopy. The macrophages were plated on plastic flasks and after the interaction they were fixed for 60 minutes in a solution containing $1 \%$ glutaraldehyde, $4 \%$ paraformaldehyde, $1 \mathrm{mM} \mathrm{CaCl}_{2}$ in $0.1 \mathrm{M}$ cacodylate buffer, $\mathrm{pH} 7.2$. Thereafter the cells were washed overnight in the same buffer, scraped off with a "rubber policeman", collected by centrifugation and post fixed for $1 \mathrm{~h}$ in a solution containing $1 \% \mathrm{OsO}_{4}, 0.8 \%$ ferricyanide in $0.1 \mathrm{M}$ cacodylate buffer, pH 7.2, supplemented with $2.5 \mathrm{mM} \mathrm{CaCl}_{2}$, dehydrated in acetone and embedded in Epon. Thin sections were stained with uranyl acetate and lead citrate.

Cationized Ferritin. Internalization of macrophage's anionic sites during ingestion of opsonized erythrocytes were observed with cationized ferritin (CF). Initially the macrophage cultures were rinsed with Eagle's medium without serum and incubated for 30 minutes at $4^{\circ} \mathrm{C}$ in the presence of $100 \mu \mathrm{g} / \mathrm{ml}$ cationized ferritin (Sigma Chemical Company, USA). Thereafter, the cultures were rinsed and allowed to interact for 5 and 60 minutes at $37^{\circ} \mathrm{C}$ in the presence of EIgG. After interaction the cultures were fixed and processed for electron microscopy as described above.

Surface labeling with lectins. Colloidal gold particles averaging $15 \mathrm{~nm}$ in diameter were prepared as described elsewhere
(11). Wheat germ agglutinin (WGA) and horseradish peroxidase (HRP) were directly conjugated to colloidal gold, provided that optimal conditions for complex formation were well determined. Stock solutions of WGA and peroxidase gold complexes were stored at $4^{\circ} \mathrm{C}$. Both direct and indirect labeling methods were applied to alive macrophages for the localization of cell surface lectin-binding sites. Direct detection of wheat germ agglutinin binding sites was carried out as follows: macrophages previously cultivated as described above, were rinsed in Eagle's medium without serum and incubated for 30 minutes at $4^{\circ} \mathrm{C}$ in the presence of gold-labeled WGA (1 : 10 dilution in PBS, pH 7.2). For detection of Con-A binding sites an indirect cytochemical labeling method was used. Alive cells were incubated for $15 \mathrm{~min}$ at $4^{\circ} \mathrm{C}$ in the presence of 100 $\mu \mathrm{g} / \mathrm{ml}$ Con-A in PBS, pH 7.2, rinsed at $4^{\circ} \mathrm{C}$ and then incubated for 15 minutes at $4^{\circ} \mathrm{C}$ in the presence of gold-labeled peroxidase (diluted $1: 10$ in PBS pH 7.2). Some monolayers were immediately rinsed, fixed and processed for electron microscopy. Others were rinsed and allowed to interact with EIgG for 60 minutes at $37^{\circ} \mathrm{C}$, and then washed, fixed and routinely processed for electron microscopy.

Freeze-fracture. After interaction the cells were fixed for $1 \mathrm{~h}$ in $2 \%$ glutaraldehyde, in $0.1 \mathrm{M}$ cacodylate buffer, $\mathrm{pH} 7.2$, washed twice in the same buffer and gradually exposed to ascending concentrations of glycerol in $0.1 \mathrm{M}$ cacodylate buffer until a final concentration of $15 \%$ glycerol was attained. The cells remained in $15 \%$ glycerol in cacodylate buffer overnight and after one day were infiltrated in glycerol $30 \%$ for 3 hours. A drop of cell suspension was then mounted on Balzers support disks and rapidly frozen in the liquid phase of Freon 22 cooled by liquid nitrogen. Freeze-fracturing was carried out at $-115^{\circ} \mathrm{C}$ in a Balzers apparatus. The cells were shadowed with platinum/carbon at $2 \cdot 10^{-6}$ Torr immediately after fracturing. Replicas were recovered in distilled water, cleaned with sulphuric acid and sodium hypochloride, mounted on 200 mesh grids and examined in a transmission electron microscope.

\section{RESULTS}

Endocytic index. Table I shows that using an EIgGmacrophages ratio adjusted to $10: 1$ about $35 \%$ of the macrophage ingested the erythrocytes after an interaction time of 15 minutes, with a mean number of 1.5 EIgG per macrophage; after 30 minutes of interaction $59 \%$ of the macrophages ingested the opsonized erythro-

Table I. INGESTION OF IgG-COATED ERYTHROCYTES BY RESIDENT PERITONEAL MOUSE MACROPHAGES*.

\begin{tabular}{cccc}
\hline \multirow{2}{*}{ Time of interaction (min) } & \multicolumn{1}{c}{ Indexes } \\
\cline { 2 - 4 } & $\begin{array}{c}\text { \% of macrophages } \\
\text { with erythrocytes }\end{array}$ & $\begin{array}{c}\text { Mean number of } \\
\text { erythrocyte per macrophage }\end{array}$ & Endocytic Index \\
\hline 15 & $35+3$ & $1.5+0.1$ & 53 \\
30 & $59+4$ & $2.8+0.2$ & 163 \\
60 & $82+6$ & $3.1+0.2$ & 250 \\
\hline
\end{tabular}

\footnotetext{
* Data from one typical experiment.
} 


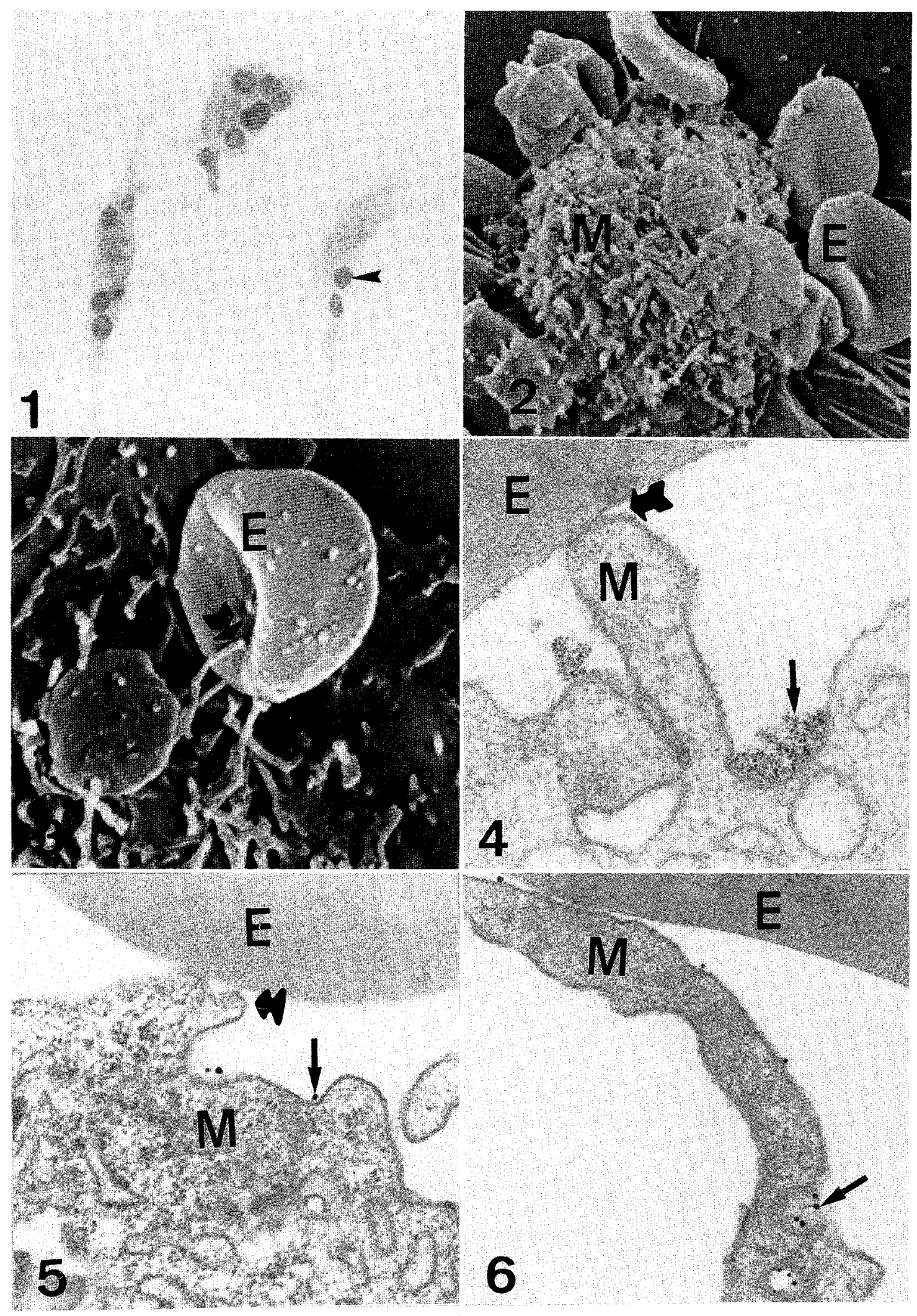

Fig. 1-6. 
cytes with a mean number of 2.8 particles per cell. After 60 minutes of interaction $82 \%$ of the macrophages contained a mean number of $3.1 \mathrm{EIgG}$. The endocytic index was calculated by multiplying the percentage of macrophages that ingested the EIgG and the mean number of EIgG per macrophage (Table I, last column). It is important to point out that while some cells ingested few EIgG, others ingested a large number (Fig. 1). In controls no significant ingestion of uncoated erythrocytes was observed (not shown).

Scanning electron microscopy. Observations of macrophages after adherence to glass surface showed that some cells spread easily while others did not spread. Variations on cell surface were also seen: some cells presented many filiform projections resembling short microvilli while others had few. Images indicative of adhesion of the EIgG to macrophages were seen (Figs. 2-3).

Cationized ferritin. When living macrophages were incubated at $4^{\circ} \mathrm{C}$ in the presence of cationized ferritin and then fixed, a uniform labeling on the whole cell surface was observed (not shown). When macrophages previously labeled with $\mathrm{CF}$ at $4^{\circ} \mathrm{C}$ were incubated in the presence of opsonized erythrocytes at $37^{\circ} \mathrm{C}$ cationized ferritin particles did not interfere with the ingestion of the IgG-coated erythrocytes. In addition, no CF were seen in the region of adhesion, of EIgG-macrophage (Fig. 4) so that opsonized erythrocytes were incorporated into phagosomes lined by a membrane which was not labeled. After an interaction time of 60 minutes some vesicles labeled with cationized ferritin particles appeared in: a) the perinuclear region (Fig. 7); b) close to the phagosomes containing erythrocytes (Fig. 8); and c) even within the phagosomes (Fig. 9). After prolonged incubation times $(1 \mathrm{~h})$ cationized ferritin particles recycled back to the cell surface and were discharged into the extracellular medium where they tend to form aggregates which occasionally were bound to the cell surface (Fig. 10).

Lectins. When living macrophages were incubated at $4^{\circ} \mathrm{C}$ in the presence of gold-labeled probes (WGA and HRP) for localization of WGA and Con A binding sites and then fixed, labeling density was particularly higher on the surface projections. When macrophages previously labeled with the lectins at $4^{\circ} \mathrm{C}$ were incubated at $37^{\circ} \mathrm{C}$ in the presence of IgG-coated erythrocytes, two processes were observed: (a) redistribution of the lectin-binding sites (Figs. 5-6) and (b) interiorization of the opsonized erythrocytes by a typical phagocytic process. These two processes were independent so that no gold particles were seen in the newly formed phagosome. After an interaction time of 60 minutes the following compartments were labeled: a) an irregular and complex tubulo-vesicular system (Fig. 11), and b) large vesicles located near the nucleus (Fig. 12). The gold particles were found either associated with membrane lining the vesicles or in their matrix, which usually contained a membranous material. Some of these labeled vesicles were seen in close contact with phagosomes containing erythrocytes (Fig. 13). Gold particles were also seen within the erythrocyte-containing phagosomes, even in the inner portion of the erythrocyte (Fig. 13). After an interaction time of 60 minutes the gold particles were seen in small peripheral vesicles and on the macrophage surface, where they appeared in patches (Fig. 14). It is important to point out that similar results were obtained when either Con A or WGA binding sites were visualized. Therefore only results obtained using gold-labeled WGA are shown here.

Freeze-fracture. Freeze-fracture replicas of macrophages that ingested IgG-coated erythrocytes showed cells cleaved through the cytoplasm or the hydrophobic region of cell membranes, exposing surfaces of the inner or the outer membrane halves. Images of the phagosomal membrane engulfing erythrocytes which still showed a random distribution of intramembranous particles (IMP) on both fracture faces of the plasma membrane were seen (Fig. 15). However, some protusions and depressions were seen. The majority of ingested EIgG presented protusions and depressions, and aggregations of intramembranous particles so that large areas without IMP could be seen, specially on the $\mathrm{P}$ fracture face (Fig. 16). Observing the macrophage cytoplasm near the endocytic vacuole containing opsonized erythrocytes we could see several vacuoles, possibly lysosomes (Figs. 15, 16). Although a quantitative study was not carried out, the distribution of membrane particles on both faces of the membrane lining the phagosome seemed to be similar to that observed in the plasma membrane.

\section{DISCUSSION}

Over the past decade it has become clear that macrophages express specific receptors for many ligands including those for the Fc region of the immunoglobulins. Sheep red blood cells opsonized with rabbit antisheep erythrocyte IgG have been used as a model for the study of the macrophage Fc-receptor (36). As a conse-

Fig. 1. Macrophages that ingested IgG-coated erythrocytes (arrowhead) as seen by light microscopy. $\times 500$.

Figs. 2-3. Scanning electron micrographs showing adhesion of IgG coated erythrocytes (E) to the macrophage (M) surface. Many filiform projections emerge from the macrophage surface and extend as far as the erythrocyte (arrow in Fig. 3). Fig. 2: $\times 16.300 ;$ Fig. 3: $\times 10.000$.

Figs. 4-6. Transmission electron microscopy showing macrophages (M) previously labeled with cationized ferritin particles (Fig. 4) or gold-labeled lectins (Figs. 5-6) allowed to interact with opsonized red blood cells (E) for 5 minutes at $37^{\circ} \mathrm{C}$. No particles were seen in adhesion areas (thick arrow). The ligand is internalized through little pits (coated or not) before erythrocyte ingestion. Fig. 4: $\times 75.000 ;$ Fig. 5-6: $\times 65.000$ 


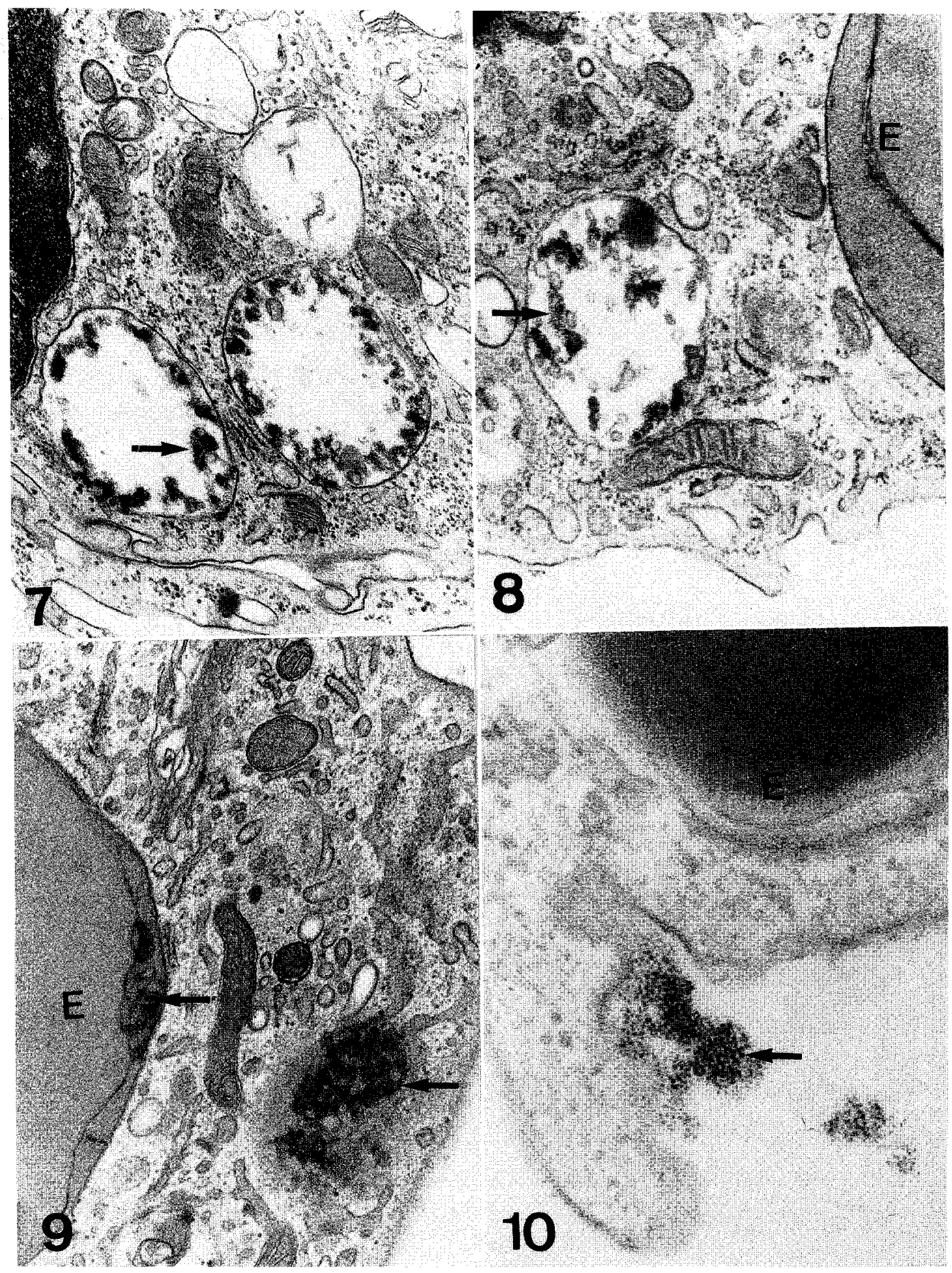

Figs. 7-10. Images of thin sections of macrophages labelled with cationized ferritin (arrows) before interaction with opsonized erythrocytes (E) and seen in the transmission electron microscope. Peripheral vesicles labeled with CF particles (Fig. 7) and located close to the EIgG-containing vacuole (Figs. 8-9) were seen. In some cases cationized ferritin particles were seen within the erythrocyte-containing phagosome (Fig. 9) and even in patches localized outside the cell (Fig. 10). Figs. 7-9: $\times 41.000$; Fig. 10: $\times 102.000$ 


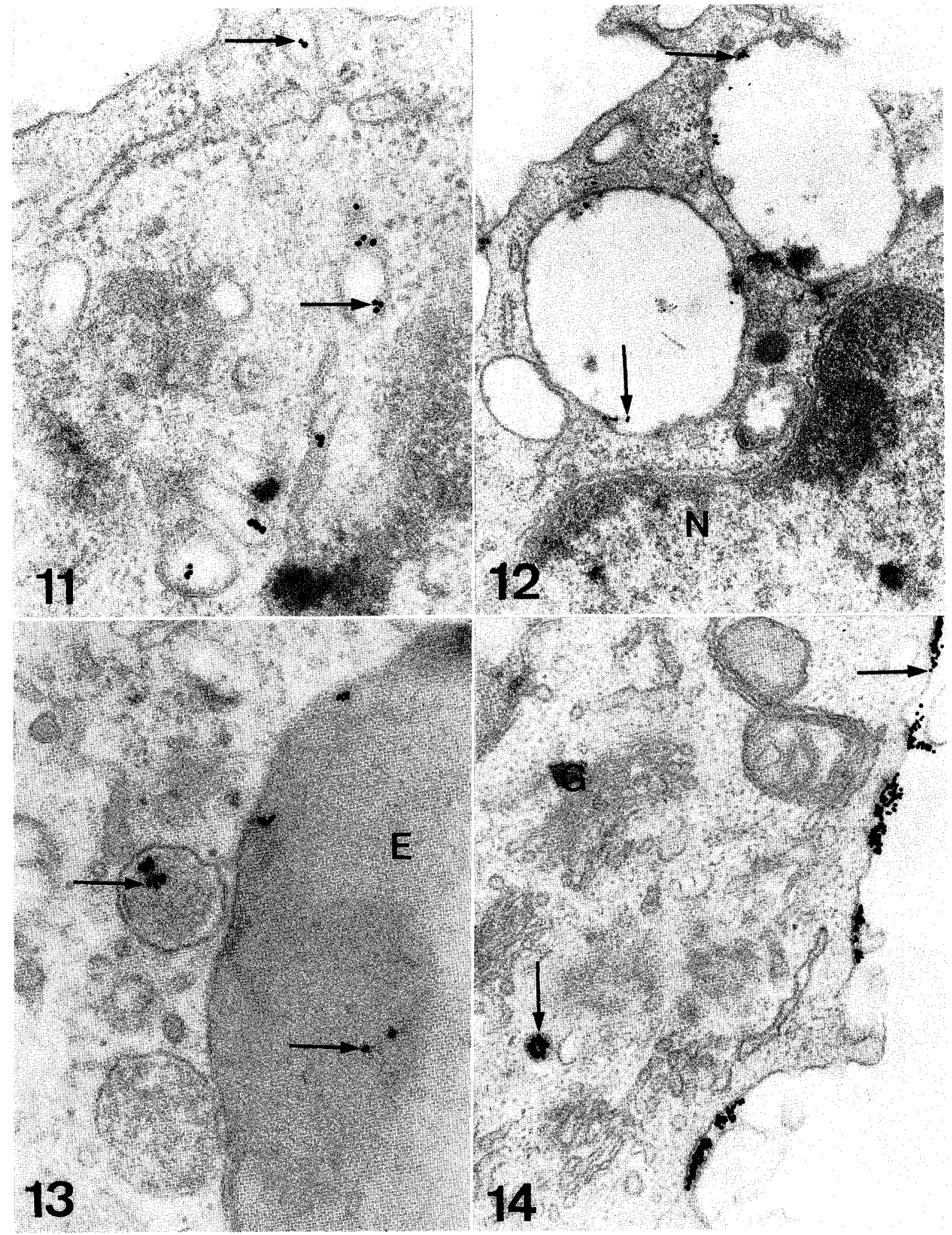

Figs. 11-14. 


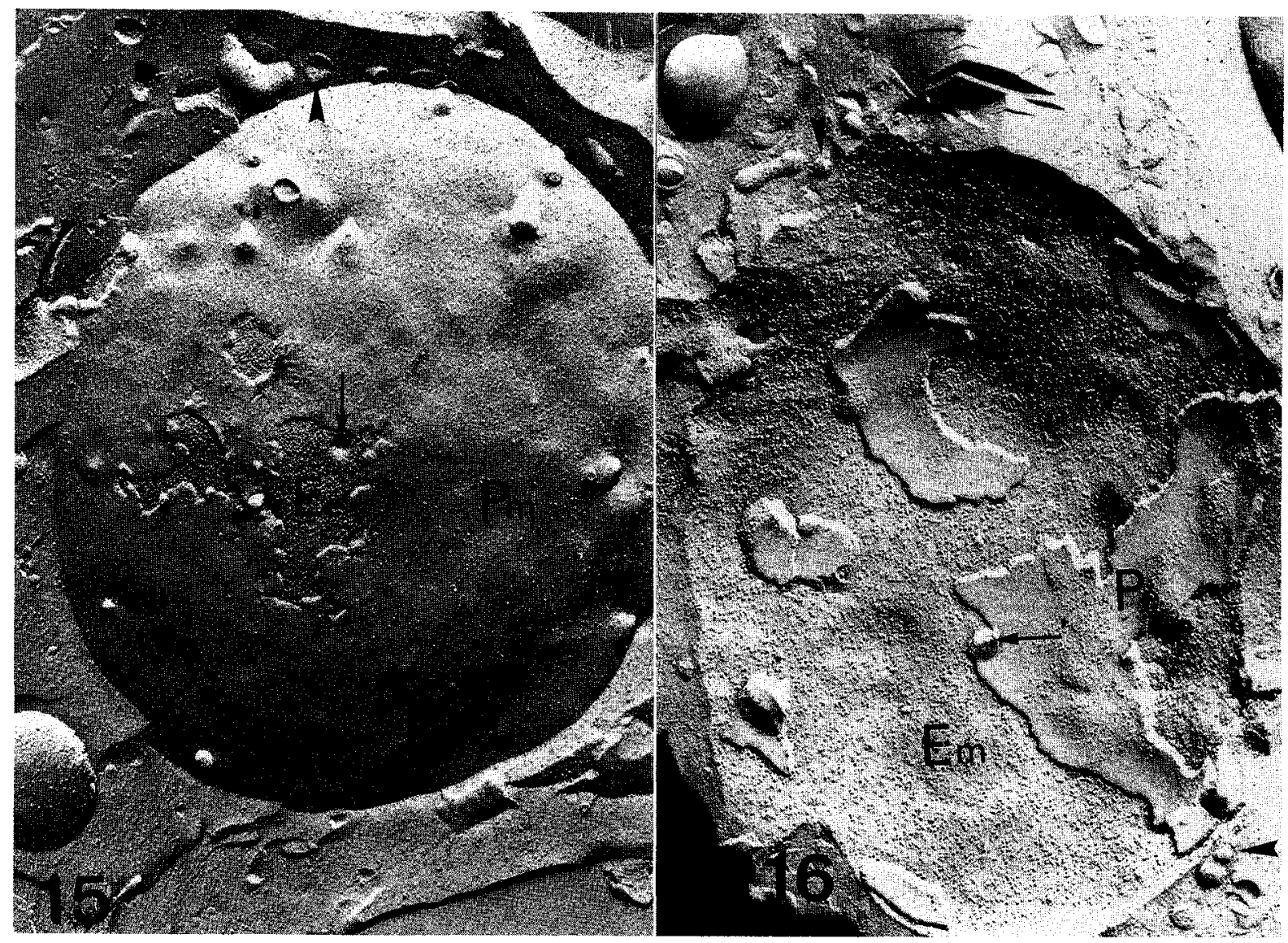

Figs. 15-16. Freeze-fracture images of macrophages that ingested opsonized erythrocyte. Fig. 15. The convex protoplasmic face of the phagosomal membrane $(\mathrm{Pm})$ and a small portion of the extracellular face of the EIgG (Ee) still showing a normal morphology with randomly distributed intramembranous particles can be seen. Figure 16 shows the extracellular (concave) face of a phagosomal membrane (Em) involving a opsonized erythrocyte whose membrane shows aggregated particles on the $\mathrm{P}$ face (Pe). Small protusions (arrows) that may represent sites of lysosome fusion, and small cytoplasmic vesicles (arrowheads) that may represent lysosomes close to the EIgG-containing-vacuole could be observed. Fig. 15: $\times 21.000$; Fig. 16: $\times 28.000$.

quence of IgG-coated erythrocyte-macrophage interaction, complex changes take place at the macrophage plasma membrane-cytoskeleton interface leading to the internalization of the particle $(13,14)$. Since the plasma membrane is a fluid structure it is possible that only some of its components are internalized together with the lipid bilayer while others remain in the plasma membrane.

We used cationized ferritin particles (8) as a probe for the localization of anionic sites on the macrophage surface and to determine if these sites are internalized during the process of formation of phagosomes containing IgG-coated erythrocytes. Studies carried out in many eukaryotic cells have shown that sialic acid resi- dues associated with glycoproteins or glycolipids, are the major component responsible for the net negative surface charge, although other anionic groups such as sulphate, found in glycosaminoglycans and ionized phosphate, found in phospholipids, also contribute to the surface charge (5). Studies on T. cruzi (22), and $L$. mexicana $(25,30)$ have shown that anionic sites of macrophages labeled with cationized ferritin are not incorporated into vacuoles containing these parasites. Interesting results were obtained with Toxoplasma gondii and Saccharomyces cerevisiae. It was shown that surface anionic sites of macrophages were internalized during ingestion of untreated but not of antibody-coated $T$. gondii (6). Buchi and de Souza (1992) observed that anionic

Figs. 11-14. Images of macrophages incubated in the presence of gold labeled WGA before interaction with opsonized erythrocytes (E). The lectin binding sites are interiorized and initially associated with an irregular and complex tubulovesicular system (Fig. 11), and concentrate into large perinuclear vacuoles (Fig. 12). Vesicles were seen close to EIgG-containing-phagosomes where some gold particles were also seen (Fig. 13). Gold particles were also seen on the macrophage surface suggesting recycling of lectin-binding-sites (Fig. 14). Fig. 11: $\times 80.000 ;$ Fig. 12: $\times$ 32.000; Fig. 13: $\times 64.000$; Fig. 14: $\times 50.000$. 
sites were interiorized together with $S$. cerevisiae, and subsequently the cationized ferritin particles were seen in small vesicles formed from the membrane lining the yeast-containing-vacuoles, suggesting a recycling mechanism of anionic sites incorporated during receptor-mediated phagocytosis. When antibody-coated-erythrocytes were allowed to interact with macrophages, two different and independent mechanisms simultaneously occur: (a) phagocytosis of IgG-coated erythrocytes and endocytosis of anionic sites, so that CF particles were not seen in newly-formed phagosomes. However, later on gold particles were seen within the phagosomes, indicating that lysosome-phagosome fusion took place. Our present results show that anionic sites of resident peritoneal macrophages are not internalized during Fc receptor-mediated phagocytosis of erythrocytes.

Our present observations using IgG-coated erythrocytes show that two lectin-binding sites are excluded from the portion of the macrophage plasma membrane involved in the formation of the phagosome. However, these binding sites are independently interiorized appearing in cytoplasmic vacuoles. We did not characterize in detail the various types of vesicles and vacuoles which are concentrated at the internalized lectin-binding sites. However, based on previous studies $(3,15,17$, $19,27)$, it was possible to estimate that they correspond to early and late endosomes, as well as typical lysosomes. After an incubation time of 60 minutes it was evident that some of the lectin-labeled cytoplasmic vesicles fused with IgG-coated erythrocytes. These observations agree with those made by Diaz et al. (1989) and Rabinowitz et al. (1992), which concluded that endosome fusion is a dynamic process which comprises multiple fusion of both plasma membrane-derived endosomes and phagosomes. An interesting observation is that showing the presence of gold-labeled lectins on the surface of macrophages incubated for 60 minutes. It has been shown previously that macrophages interiorize all lectins bound to their surface with in a few minutes. Therefore, the observation of surface labeling after 60 minutes suggests the recycling of binding sites. A similar phenomenon is also observed with cationized ferritin.

Intramembranous particles are assumed to represent integral proteins or protein-lipid complexes inserted into the hydrophobic domains of the membrane bilayer. Freeze-fracture studies carried out in erythrocytes have shown that the protoplasmic face presents a higher density of intramembranous particles than the $E$ face $(18,26,34)$. Our present observations of freeze-fracture replicas of $\operatorname{IgG}$-coated erythrocytes, which were allowed to interact with macrophages, show that the membrane lining the phagosome resembles the macrophage plasma membrane. This is an unexpected observation in view of the fact that membrane-associated macromole- cules such as anionic sites and lectin-binding sites are not interiorized. The membrane of erythrocytes located within the phagocytic vacuole showed aggregation of membrane particles, which were especially evident on the $\mathbf{P}$ fracture face, as well as some small protrusions. It is possible that these modifications of the erythrocyte plasma membrane are due to fusion of macrophage lysosomes with the phagosome.

In conclusion our present observations, in association with previous studies $(4,6,7,21,25,32,35)$, support the view that macrophages possess mechanisms to control the nature of the components of their surface membrane which are interiorized during an endocytic process.

Acknowledgments. The authors thank for Dr. E.A. Buchi for reading the manuscript, Miss C.M. Tassini, Mr. Sebastiao Cruz and Mrs. Marlene Cazuza for the technical support and Mrs. V.R. Pionteke for the photographic work. This work was partially carried out in the Centro de Microscopia Eletronica-Universidade Federal do Parana and has been supported by CAPES, CNPq and FINEP.

\section{REFERENCES}

1. Bar-Shavit, Z. and Goldman, R. 1976. Con-A mediated attachment and ingestion of yeasts by macrophages. Exp. Cell Res., 99: 221-226.

2. Bendayan, M., Nanci, A., and Kan, F.W.K. 1987. Effect of tissue processing on colloidal gold cytochemistry. J. Histochem. Cytochem., 35: 983-996.

3. BRAEL, W.A. 1981. Fusion of endocytic vesicles in a cell-free system. Proc. Natl. Acad. Sci. USA, 84: 1137-1141.

4. BUCHI, D.F. and DE SOUZA, W. 1992. Internalization of surface components during ingestion of Saccharomyces cerevisiae by macrophages. J. Submicrosc. Cytol. Pathol., 24: 135-141.

5. Capo, C., Bongrand, P., Benoliel, A.M., Ryter, A. and Depieds, R. 1981. Particle-macrophage interaction: role of surface charges. Ann. Immunol. (Inst. Pasteur), 132 D: 165-173.

6. Carvalho, L. and De Souza, W. 1989. Cytochemical localization of plasma membrane enzyme markers during interiorization of tachyzoites of Toxoplasma gondii by macrophages. $J$. Protozool., 36: 164-170.

7. Carvalho, L. and De Souza, W. 1990 . Internalization of surface anionic sites and phagosome-lysosome fusion during interaction of Toxoplasma gondii with macrophages. Eur. J. Cell Biol., 51: 211-219.

8. Danon, D., Goldstein, L., Marikovsky, Y., and Skutelsky, E. 1972. Use of cationized ferritin as a label of negative charges on cell surface. J. Ultrastruct. Res., 38: 500-510.

9. Diaz, R., Mayorga, L.S., Mayorga, L.E., and Stahl, P. 1989. In vitro clustering and multiple fusion among macrophage endosomes. J. Biol. Chem., 264: 13171-13178.

10. Edelson, P.J. and CoHN, Z.A. 1976. 5'-nucleotidase activity of mouse peritoneal macrophages. I-Synthesis and degradation in resident and inflammatory populations. J. Exp. Med., 144: 1581-1595.

11. FRENS, G. 1973. Controlled nucleation for the regulation of the particle size in monodisperse gold suspension. Nature, 241: $20-22$.

12. Goldman, R. 1977. Lectin mediated attachment and ingestion 
of yeast cells and erythrocytes by hamster fibroblast. Exp. Cell Res., 104: 325-330.

13. Greenberg, S., Burridge, K., and Silverstein, S.C. 1990. Colocalization of F-actin and talin during Fc Receptor mediated phagocytosis in mouse macrophage. J. Exp. Med., 172: $1853-1856$

14. Greenberg, S., El Khoury, J., Di Virgilio, F., Kaplan, E.M., and Silverstein, S.C. 1991. $\mathrm{Ca}^{+}$independent F-actin assembly and disassembly during $\mathrm{Fc}$ receptor-mediated phagocytosis in mouse macrophages. J. Cell Biol., 113: 757-767.

15. Gruenberg, J. and Howell, K.E. 1989. Membrane traffic in endocytosis: insights from cell-free assays. Ann. Rev. Cell Biol., 5: $453-481$.

16. Hirata, J., Fernandez-Botran, R., and Suzuki, T. 1987. Relationship between $\mathrm{Fc} 2 \mathrm{~b}$ receptor and adenylate cyclase of a murine macrophage-like cell line P388D1. Biochemistry, 26: 4183-4192.

17. Hopkins, C.R., Gibson, A., Shipman, M., and Miller, K. 1990. Movement of internalized ligand-receptor complexes along a continuous endosomal reticulum. Nature, 346: 335337.

18. Hui, S.W., Stewart, C.M., and Cherry, R.J. 1990. Electronmicroscopic observation of the aggregation of membrane proteins in human erythrocytes by melittin. Biochem. Biophys. Acta., 1023: 335-340.

19. Kaplan, J. and WARD, D.M. 1990. Movement of receptors and ligands through the endocytic apparatus in alveolar macrophages. Am. Physiol. Soc. Commentaries., L 263-270.

20. Lis, H. and Sharon, N. 1986. Lectin as molecules and as tools. Ann. REv. Biochem., 55: 35-63.

21. Meirelles, M.N.L., Martinez-Palomo, A., Souto-Padron, T. and DE SouzA W. 1983. Participation of Concanavalin-A binding sites in the interaction between Trypanosoma cruzi and macrophages. J. Cell Sci., 62: 287-299.

22. Meirelles, M.N.L., Souto-Padron, T., and De Souza, W. 1984. Participation of cell surface anionic sites in the interaction between Trypanosoma cruzi and macrophages. J. Submicrosc. Cytol., 16: 533-545.

23. Meirelles, M.N.L. and de Souza, W. 1986. The fate of plasma membrane macrophage enzyme markers during endocytosis of Trypanosoma cruzi. J. Submicrosc. Cytol., 18: 99-107.

24. Mellman, I.S. 1982. Endocytosis, membrane recycling and Fc receptor function. In Membrane Recycling, CIBA Foundation Symposium, 92, (D. Evered, ed.). Pittman Press, London. Pag 35-70.
25. Prmenta, P.F.P. and De Souza, W. 1988. Freeze-fracture and cytochemistry study of the interaction between Leishmania mexicana amazonensis and macrophages. J. Submicrosc. Cytol. Pathol., 20: 89-99.

26. Pinto da Silva, P., Moss, P.S., and Fudenberg, H.H. 1973. Anionic sites on the membrane intercalated particles of human erythrocyte ghost membranes. Freeze-etch localization. Exp. Cell Res., 81: 127-138.

27. Rabinowitz, S., Hosstman, H., Gordon, S., and Griffith, G. 1992. Immunocytochemical characterization of the endocytic and phagolysosomal compartments in peritoneal macrophages. J. Cell Biol., 116: 95-112.

28. Rотн, J. 1983. Aplication of lectin-gold complexes for electron microscopic localization of glycoconjugates on thin sections. J. Histochem. Cytochem., 31: 987-999.

29. Rouzer, C.A., Scott, W.A., KenYe, J., and Cohn, Z.A. 1980. Prostaglandin synthesis by macrophages requires a specific receptor-ligand interaction. Proc. Natl. Acad. USA, 77: 4279-4282.

30. Saraiva, E.M.B., Vannier-Santos, M.A., Silva-Filho, F.C., and DE SouzA, W. 1989. Anionic site behavior in Leishmania and its role in the parasite-macrophage interaction. J. Cell Sci., 93: 481-489.

31. Spicer, S.S. and Schulte, B.A. 1992. Diversity of cell glycoconjugates shown histochemically: a perspective. J. Histochem. Cytochem., 40: 1-38.

32. Steinman, R.M., Mellman, I.S., Muller, W.A., and Cohn, Z. 1983. Endocytosis and the recycling of plasma membrane. J. Cell Biol., 96: 1-16.

33. Suzuki, T., Saito-Taki, T., Sadasivan, R., and NitTa, T. 1982. Biochemical signal transmitted by $\mathrm{Fc}$ receptors: Phospholipase $\mathrm{A}_{2}$ activity of $\mathrm{Fc} 2 \mathrm{~b}$ receptor of murine macrophage cell line P3888 $\mathrm{D}_{1}$. Proc. Natl. Acad. USA, 79: 591-595.

34. Tillack, T.W., Scott, R.E., and Marchesi, V.T. 1972. The structure of erythrocyte membrane studied by freeze-etching. II. Localization of receptors for phytohemaglutinin and influenza virus to the intramembranous particles. J. Exp. Med., 135: 1209-1227.

35. Tsan, M.F. and BerLin, R.D. 1971. Effect of phagocytosis on membrane transport of nonelectrolytes J. Exp. Med., 134: 1016-1035.

36. Unkeless, J.C., Fleit, H., and Mellman, I.S. 1981. Structural aspects and heterogeneity of immunoglobulin Fc Receptors. Adv. Immunol., 31: 247-260.

(Received for publication, February 2, 1993 and in revised form, November 25,1993 ) 